\title{
Pelvic Floor Dysfunction, the Role of Imaging and Reconstructive Surgery
}

\author{
Abdel Karim M El Hemaly, Laila A Mousa, Asim Kurjak, Ibrahim M Kandil, Ahmad G Serour
}

\section{ABSTRACT}

We are putting forward three novel concepts describing the pathophysiology concerning:

- Micturition, factors that control urinary continence and different types of urinary incontinence.

- Genital organs support and genital prolapse.

- Defecation, causes of fecal incontinence (FI).

I. Urinary continence depends on high urethral pressure (Pura) which depends upon two factors: One inherent and one acquired.

1. The inherent factor is the tough strong collagen layer constituent of the internal urethral sphincter (IUS), that creates the high wall tension necessary for keeping high urethral pressure (Pura). The IUS is a collagen-muscle tissue cylinder that extends from the bladder neck to the perineal membrane in both sexes.

2. The acquired factor, which is high alpha-sympathetic tone at the IUS gained from learning and training in early childhood, keeps it contracted and the urethra closes all the time until there is a need or a desire to void as social circumstances allow. Injury to one or both factors leads to urinary incontinence.

II. The vagina is a cylinder of collagen-elastic-muscle tissues. The strong tough collagen sheet is responsible for the upright position of the vagina. The main function of the pelvic ligaments is to assign the pelvic organs to their anatomical site and keeps the pelvic organs in situ. Childbirth trauma damages the collagen layer due to overstretching of the vagina and leads to flabby and redundant vaginal walls with subsequent vaginal prolapse. When the pelvic ligaments suffer most of the trauma, the insult will lead to weakness of the pelvic ligaments, leading to vault and uterine prolapse.

III. The integrity of both anal sphincters, internal anal sphincter (IAS) and external anal sphincter (EAS) is an essential factor in keeping fecal continence. Fecal continence also depends on strong pelvic floor muscles which keep an angle between the rectum and the anal canal. In addition, it depends on an acquired behavior, gained by learning and training in early childhood of maintaining high alpha-sympathetic tone at the IAS keeping the anal canal empty and closed all the time until there is a desire and/or a need to pass flatus and/ or stool and there are favorable social circumstances.

The intimate relation of the IUS with the anterior vaginal wall and the IAS with the posterior vaginal wall exposes them to the childbirth trauma with subsequent damage. This will lead to stress urinary incontinence (SUI) and FI in addition to vaginal prolapse.

Therefore, we have innovated an operation to treat SUI, FI and vaginal prolapse. 'Urethro-ano-vaginoplasty' repair operation. It consists of anterior and posterior sections. In the anterior section, we have corrected the SUI and the anterior vaginal wall descent through the following steps:

1. Expose the IUS and mend its torn wall.
2. Strengthen the anterior vaginal wall by overlapping the two vaginal flaps, and hence we can add extra support to the mended IUS and preserve the body collagen.

In the posterior section, we have the following:

1. Exposed the IAS and mended the torn sphincter.

2. We have approximated the two-levator ani muscles.

3. Strengthened the posterior vaginal wall by overlapping the two vaginal flaps; as such, we would have also added extra support to the mended IAS and kept the natural body collagen.

4. We repaired the perineum.

Keywords: Micturition, U rinary continence, Urinary Incontinence, Stress urinary incontinence, Genital prolapse and fecal incontinence.

How to cite this article: EI Hemaly AKM, Mousa LA, Kurjak A, Kandil IM, Serour AG. Pelvic Floor Dysfunction, the Role of Imaging and Reconstructive Surgery. Donald School J Ultrasound Obstet Gynecol 2013;7(1):86-97.

\section{Source of support: Nil}

\section{Conflict of interest: None}

\section{INTRODUCTION}

The female pelvis contains three major tracts that lie on and traverse the pelvic floor. These are the urinary bladder (UB) and the urethra anteriorly, the female genital tract in the middle, and the rectum and anal canal posterior. The pelvic floor consists of the pelvic floor muscles, mainly the levator ani muscles, and connective tissues and ligaments. The relative contributions to the structural support of the pelvic floor and its functions have been the subject of controversy. ${ }^{1,2}$ With increasing age, women can develop voiding troubles as urgency, overactive bladder, 1,3,4 frequency, nocturia and stress urinary incontinence (SUI). Other concomitant troubles, which occur, are genital prolapse, fecal incontinence (FI) and pelvic pain. ${ }^{1,5}$ All of these symptoms can be associated, to a greater or lesser extent, with pelvic floor defects. ${ }^{1}$

The first vaginal birth is especially associated with the development of prolapse, whereas additional vaginal births do not show significant increases in the odds of prolapse. ${ }^{6,7}$

We are putting forward three novel concepts describing the pathophysiology, anatomy, morphology of the structures, functions and pathology of these three tracts.

1. Micturition, factors that control urinary continence, causes of urinary incontinence and voiding troubles.

2. Genital organs support and genital prolapse.

3. Defecation, causes of FI and description of the anatomy morphology of the structures and functions of the internal anal sphincter (IAS). 


\section{MICTURITION}

The UB stores the urine, which we void through the urethra. Voiding has two stages:

First stage, before training in infancy and early childhood: As soon as the UB is full, sensation of fullness of the UB travels along the pelvic parasympathetic nerves to the spinal cord. Through spinal cord's centers, reflex parasympathetic activity (S2, 3 and 4) leads to contraction of the detrusor muscle voiding the urine through an open urethra irrespective of neither time nor place.

Second stage after training: The mother starts to teach and train her infant-child how to hold up until proper social circumstances are available. The teaching and training leads to learning how to maintain high alpha-sympathetic tone (T10-L 2) at the internal urethral sphincter (IUS) keeping it contracted and the urethra closed all the time until favorable social circumstances allow.

Sensations of bladder fullness travel along the pelvic parasympathetic (S2, 3 and 4 ) to the CNS. This allows the person, according to the social circumstances available, to choose either to retain the urine to a later time until favorable social circumstances allow, or to void. If she chooses to retain, three neuromuscular actions take place:

1. Increase of the alpha-sympathetic tone to the IUS confirming closure of the urethra.

2. The second action is inhibition of the parasympathetic impulses to the detrusor muscle inhibiting its contractions.

3. The third action is increase of the tone of the external urethral sphincter (EUS) which is a skeletal muscle innervated by voluntary NS.

When appropriate time and place are available then, controlled by the CNS, synergistic actions between the somatic and the autonomic nervous systems four neuromuscular actions take place:

1. L ow ering of the high al pha-sympathetic tone at the IUS relaxing the sphincter and opening the urethra,

2. Relaxing the EUS which is a striated muscle innervated by somatic nerve supply,

3. A ctivating pelvic parasympathetic nerves to contract the detrusor muscle and empty the UB,

4. The EUS (compressor urethrae) acts to propagate and propel the stream of urine and at the end to squeeze the urethra to expel the last drops of urine $8-13,15$ (Fig. 1).

High urethral pressure (Pura) that is much higher than vesical pressure (Pves) is the main factor that keeps urinary continence. The main causes of high Pura are as follows:

1. Structural or inherent factor, which is the tough strong collagen tissue layer constituent of the IUS' cylinder,

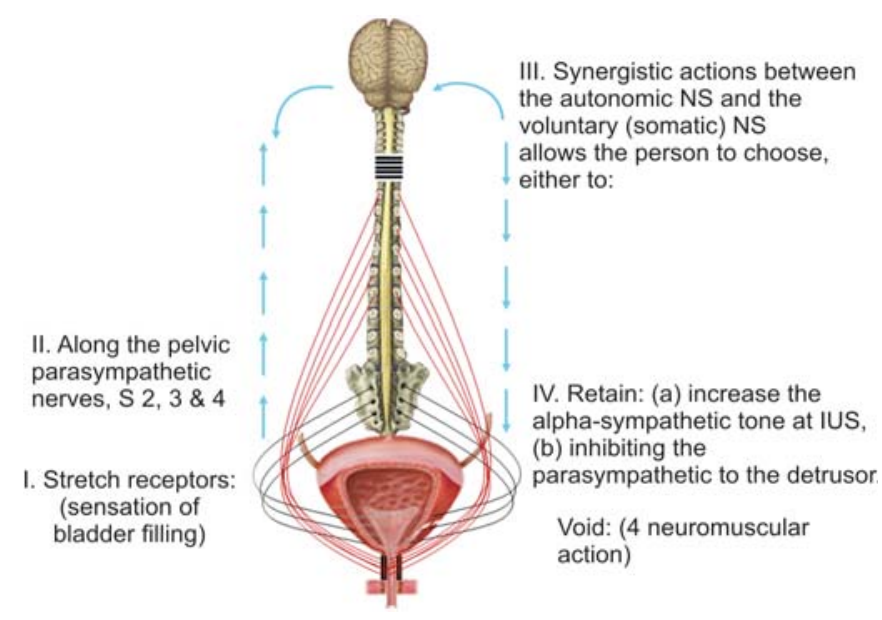

Fig. 1: The steps followed in the second stage of micturition and its CNS control. Sensations of bladder filling travels along the pelvic parasympathetic nerves S2, $3 \& 4$. Controlled by the CNS, depending on the social circumstances, synergistic neuromuscular actions take place. If time and place do not allow voiding, the woman will increase the alpha-sympathetic tone at the IUS. She will also inhibit the pelvic parasympathetic preventing detrusor contractions. In addition, she will confirm closure of the EUS. When social circumstances allow, she will inhibit the high alpha-sympathetic tone at the IUS, thus opening the urethra. She will activate the pelvic parasympathetic inducing detrusor contractions. She will relax the EUS thus allowing voiding. The EUS tone increases to allow propulsion and ejection of the stream of urine and at the end of micturition to squeeze the urethra from the last few amount of urine

which is the skeleton of the IUS, that creates the high wall tension necessary for keeping high Pura.

2. The acquired or behavior factor which is the high al phasympathetic tone at the IU S that keeps it contracted and the urethra closed all the time until there is a need or a desire to void and social circumstances allow.

Injury to one or both factors leads to drop of Pura and leakage of urine. The drop in Pura happens:

a. Physiologically when she, voluntary, inhibits the high al pha-sympathetic tone at the IU S that leads to opening the urethra and voiding occurs.

b. Pathologically, because of rupture, atrophy and degeneration of the collagen sheet of the IUS. The weak IUS will not stand against sudden rise of abdominal pressure on physical activity, as on cough, sneezing, jumping, coitus or sometimes changing postural position and urine will leak (Figs 2 to 9). The woman will be embarrassed, and a quick reflex reactive sympathetic activity will increase the existing acquired high alphasympathetic tone at the IUS, closing the urethra and preventing further urinary leakage. ${ }^{16-19}$

Childbirth trauma causes rupture of the collagen layer constituent of the IUS leading to its weakness. D rop in the estrogen level causes atrophy of the pelvic collagen and subsequent weakness. Chronic and or repeated genitourinary 
The structure of the internal urethral sphincter

It is mainly a cylinder composed of compact collagenous tissue. IT extends from the bladder neck down to the perineal membrane.

It is lined by urothelium; The muscle fibers intermingle with the collagen fibers in the middle part; the muscle layer is controlled by alpha-sympathetic nerve T10-L2
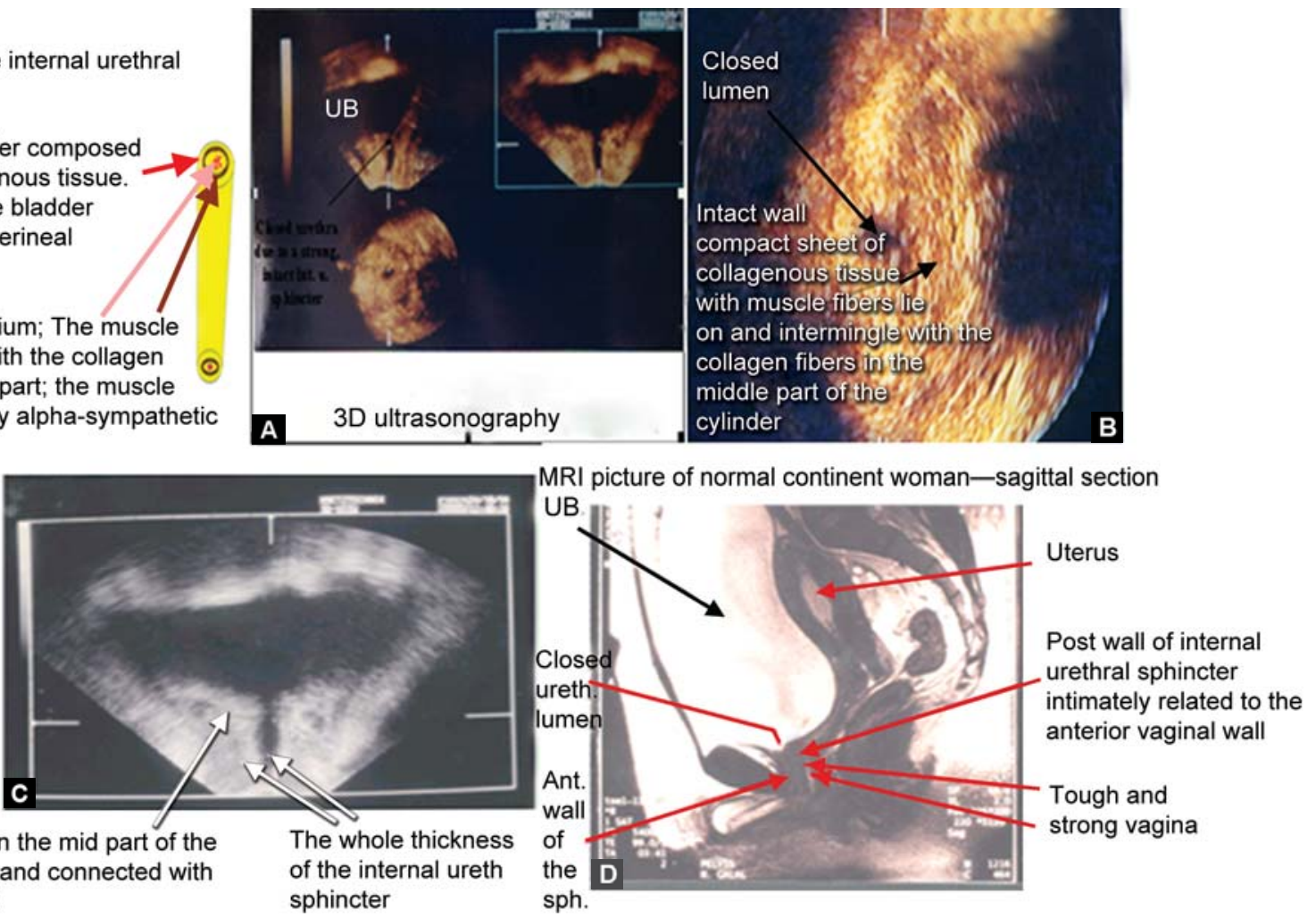
collagenous sheet and connected with the detrusor above

sphincter

Figs 2A to D: A diagram of the IUS as a cylinder of collagen-muscle lined with urothelium; and an image (A) with three-dimension ultrasound (3DUS) shows the IUS as a thick tissue cylinder that extends from the bladder neck down to the perineal membrane with muscle lying on top of collagen. The cross section in (B), shows the muscle lying on top of muscle. In (C), you can kindly notice the connection of the muscle layer above with the detrusor muscle. In (D), an MRI image of a patient with full distended UB with an intact thick IUS when compared to the normal healthy vaginal wall thickness
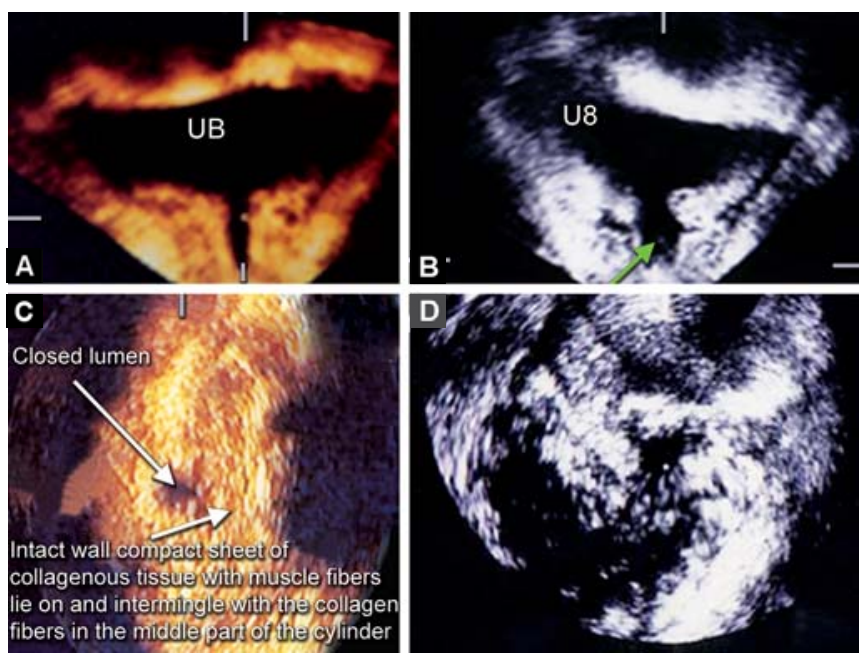

Figs 3A to D: 3D US images of the IUS. A and B are of normal IUS with intact wall, which is a collagen-muscle tissue wall, with the muscle fibers lying on the collagen layer. $C$ and $D$ are images of torn IUS; the lacerations affect more the collagen layer leading to shortening of the urethra with irregular walls as seen in C

infections causes degeneration of the collagen of the IUS and of the vagina that leads to its weakness causing SUI and vaginal prolapse (Figs 2 to 12 ).

Imaging with 3D US and MRI can demonstrate the rupture in the IUS clearly.

The level of the rupture along the cylinder of the IUS and its extent will determine the type of SUI (DO, genuine
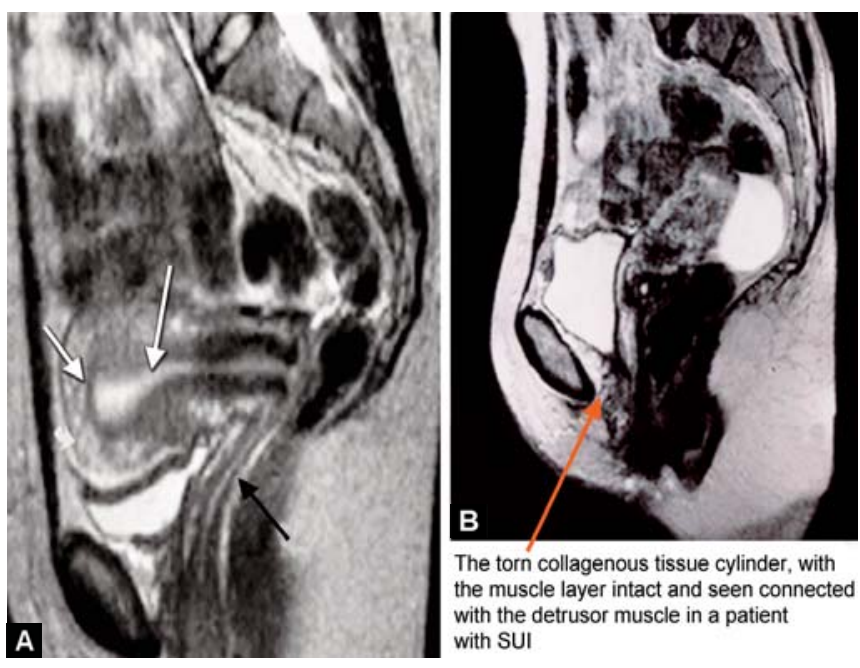

Figs 4A and B: Images that are taken with MRI, sagittal section, which show comparison between normal IUS and vagina in (A), in contrast to torn IUS and vagina in (B)

SUI or mixed type of incontinence) and the morphological shape of the urethra seen on imaging. If the rupture affects mainly the upper part of the IUS, detrusor overactivity (D O) ensues, and funneling of the bladder neck with loss of urethrovesical angle appears on imaging. When the main damage is in the lower part of the IUS, it will lead to genuine SUI and a 'flask-shape' appearance on imaging. If the 

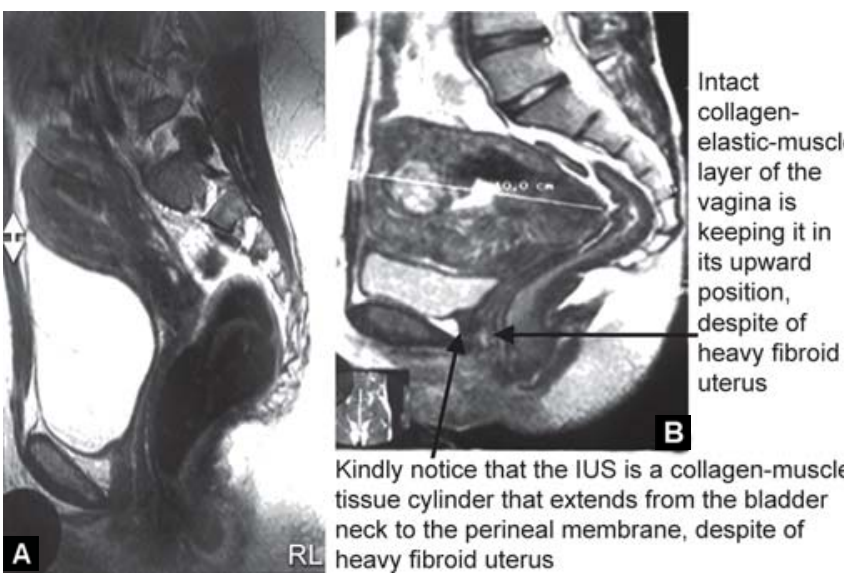

Figs 5 A and B: Images with MRI, sagittal sections, both show the IUS as a cylinder that extends from the bladder neck to the perineal membrane. The IUS is intact with a closed urethra, although there is fibroid uterus with increased abdominal pressure. The vagina is thin wall and standing up due to its tough collagen layer. The IAS is intact and the anal canal is closed, though the rectum is full in image $A$

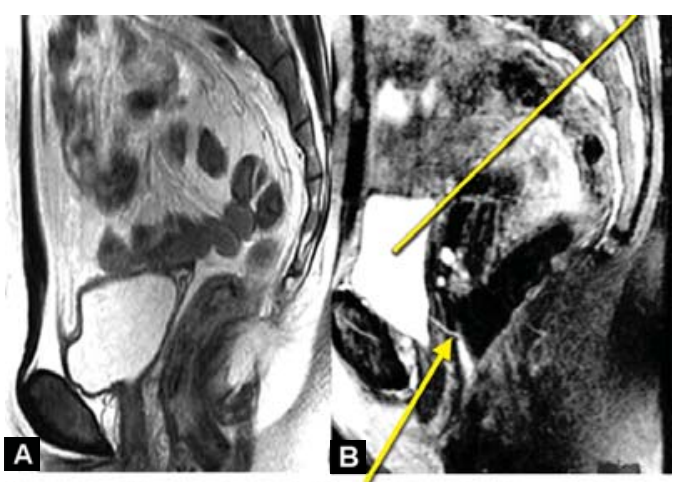

Torn weak internal urethral sphincter the damage is mainly in the upper part of the collagenous tissue cylinder causing funneling of the bladder neck and leading to $\mathrm{Dl}$ alone or mixed-type of urinary incontinence

Figs $6 \mathrm{~A}$ and $\mathrm{B}: \mathrm{MRI}$ images, sagittal section, of a patient with mullerian duct agenesis $(A)$ with absent uterus and vagina, the IUS is seen as a tissue cylinder that extends from the bladder neck to the perineal membrane with a closed urethra. In (B), the IUS is torn especially in its upper part causing funneling of the bladder neck. The vagina is torn and prolapsed as indicated by the yellow arrow

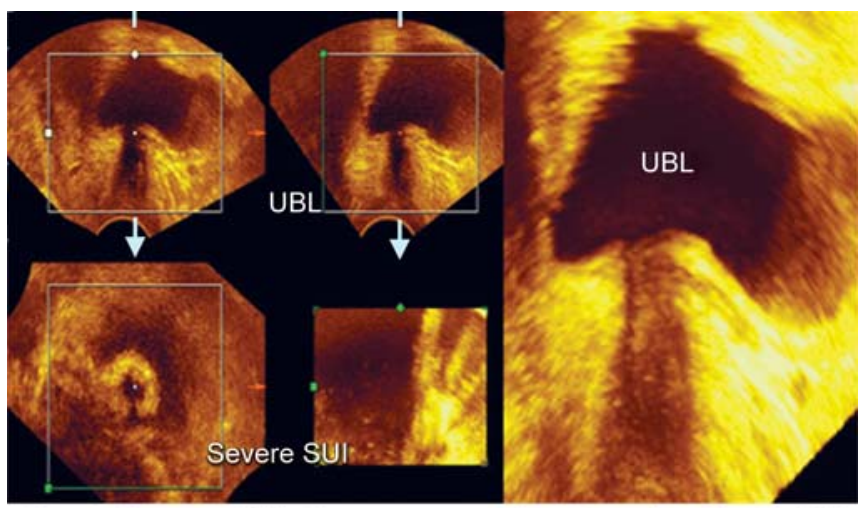

Cases with severe SUI, where you can see lacerations that affect the IUS

Fig. 7: Patients who suffer severe SUI scanned with 3D US. The IUS is torn, seen clearly in the cross section, and the urethra is open and flask shape
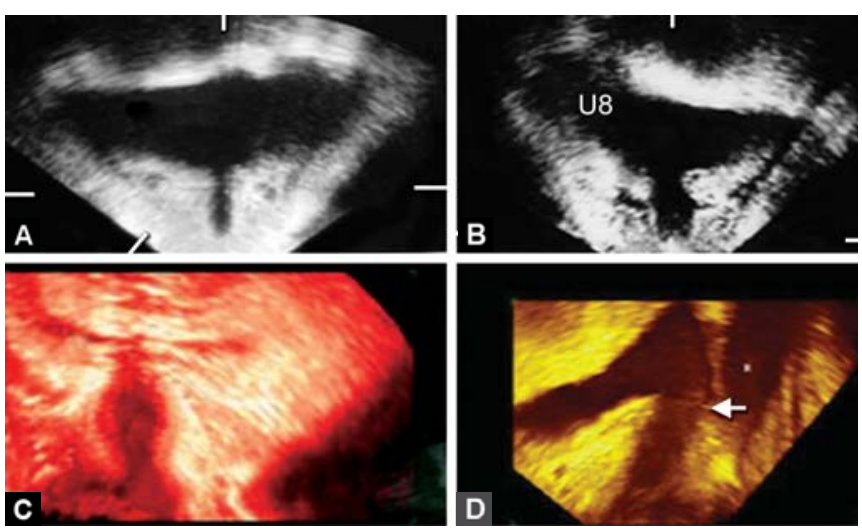

Figs 8 A to D: Images with $3 D$ US, $(A)$ is a coronal section of a normal continent woman with intact IUS, $(B)$ is a coronal section showing lacerations of the IUS affecting the whole length with irregular walls and an open dilated urethra, $(C)$ is a coronal section showing the lacerations in the IUS mainly in the lower part giving a flask-shape appearance to the urethra, (D) is a sagittal section that shows loss of the posterior urethrovesical angle; it also shows an intact IAS with a closed and empty anal canal

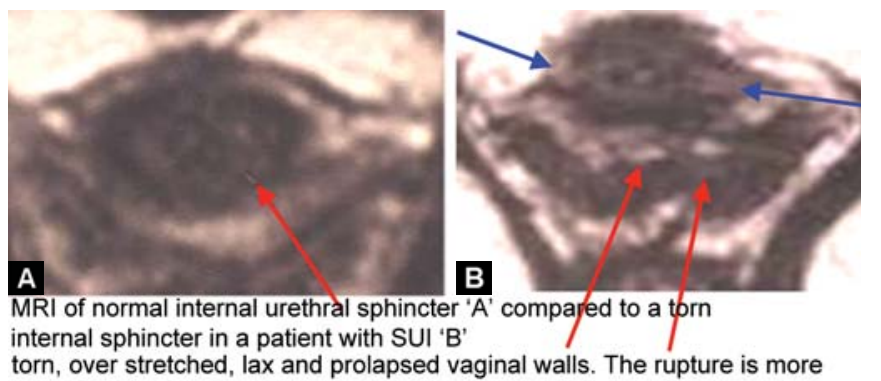
marked in the central midpart of the vaginal walls than in the periphery

Figs $9 A$ and $B$ : Images with $M R I,(A)$ is a cross section of a normal nulliparous woman with $\mathrm{H}$-shape vagina and normal cross section of an intact IUS, (B) is a cross section, which shows lacerated prolapsed vagina and lacerated IUS

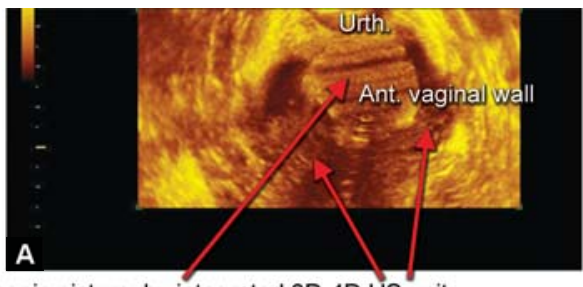

Ultrasonic picture, by integrated 3D-4D US unit showing anterior and posterior vaginal walls

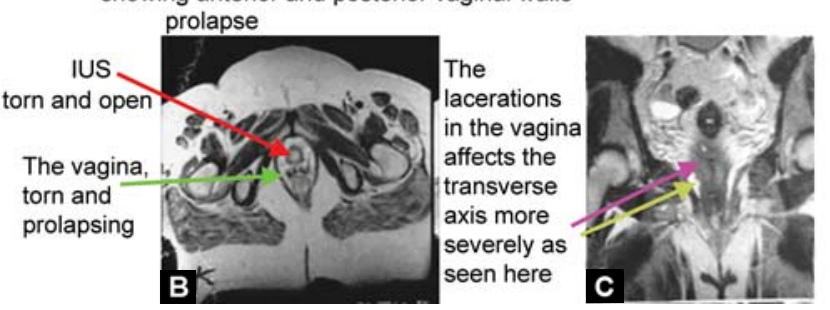

Figs 10A to C: Images with $3 D$ US (A) and MRI (B and C) of the vagina that show lacerations and prolapse of the vagina, the transverse axis of the vagina suffers most of the trauma. The IUS, which is intimately related to the anterior vaginal wall, is also lacerated and the urethra is open

damage affects the entire length of the IUS, then mixed type of urinary incontinence is the result, and a collapsed, apparent short urethra with irregular walls is seen on imaging (Figs 4 to 8). 


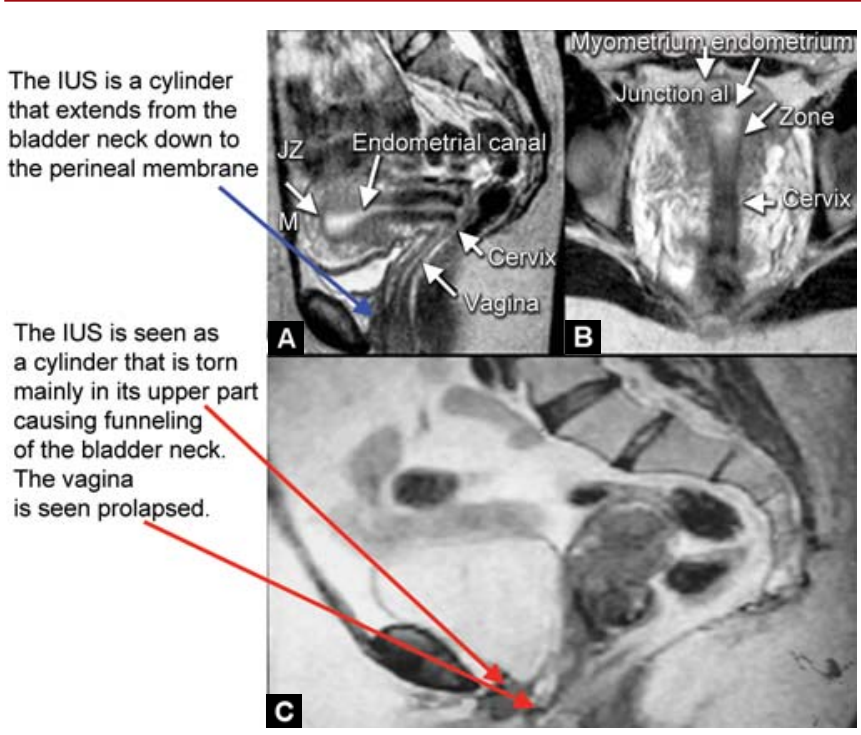

Figs 11A to C: Images with MRI, (A) is an image of a normal woman showing the IUS as a tissue cylinder that extends from the bladder neck down to the perineal membrane. The vagina is standing up thanks to its tough collagen layer, which is shown in (B). In (C), the IUS cylinder is torn more marked in its upper part that shows funneling of the bladder neck. The vagina is also torn and prolapsed
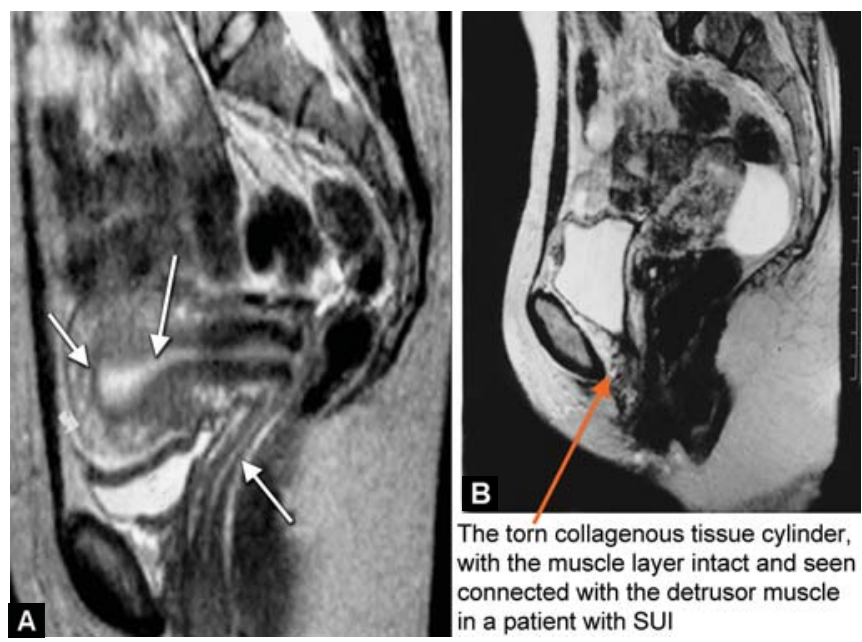

Figs $12 \mathrm{~A}$ and $\mathbf{B}$ : Images with $\mathrm{MRI}$, sagittal section, they are comparison between normal IUS and vagina in (A); in contrast to torn IUS and vagina in (B). In (A), the lower arrow points at normal vagina, which is standing up because of its tough collagen sheet

Thus, by understanding this new concept, we can explain all voiding troubles. ${ }^{8-19}$

Functional disturbances, and/or structural damage of the IUS will lead to urinary incontinence, and voiding troubles.

\section{Functional Damage of the Nervous Control of the IUS}

1. Failure to acquire the second stage of micturition leads to nocturnal enuresis. ${ }^{13-15}$ These failures can be complete failure or partial failure. Complete failure: Here there is a stop at the first stage of micturition, as the UB fills it empties irrespective to neither time nor place, leading to day and night enuresis. This occurs in about $10 \%$ of nocturnal enuresis patients.
The failure can be partial, as the bladder is full; the patient will be embarrassed of wetting herself, so she increases the al pha-sympathetic tone contracting the IU S and closing the urethra, preventing involuntary urination until she reaches the toilet. However, on sleeping this weak partial alpha-sympathetic tone will be lost and nocturnal enuresis will occur. This occurs in $90 \%$ of nocturnal enuresis patients. Therefore, the treatment of nocturnal enuresis is not by giving anticholinergic drugs, but by giving al pha-sympathomimetic drugs.

2. Sympathetic overactivity, e.g. painful stimuli (e.g. episiotomy, abdominal or pelvic surgery), leads to retention of urine. Spinal cord injury below the second lumbar neural level or spinal anesthesia, leads to loss of the pelvic parasympathetic sparing the thoracolumbar sympathetic supply will cause retention of urine or retention with overflow.

3. Sympathetic failure, like severe fear leads to transient urinary incontinence. In addition, al cohol, getting drunk may lead to transient UI.

\section{Structural damage of the IUS}

The damage can affect the whole thickness of the urethra and this will lead to true urinary incontinence.

The damage and rupture can be from inside, as after urethral instrumentation, this will lead to urethral diverticulum and post voiding dribbling.

Damage from outside due to over distension of the vagina in difficult, prolonged or multiple frequent labors will tear the collagen layer of the IUS causing SUI. In a review article de Boer et al found an association between vaginal prolapse and over active bladder. ${ }^{7}$ Other authors tried ultrasonic assessment of the bladder, urethra and pelvic organs with different results. ${ }^{20-23}$

\section{GENITAL PROLAPSE}

The vagina is a cylinder of collagen elastic muscle tissues. The strong tough collagen sheet is the one responsible for the upright position of the vagina. Childbirth trauma injures the collagen layer due to overstretching of the vagina and leads to flabby and redundant vaginal walls with subsequent vaginal prolapse (Figs 9 to 12). The injury affects the transverse axis of the vagina much more than the longitudinal axis (Figs 10A to C). The vagina becomes wider and more redundant. $V$ aginal deliveries, specially prolonged difficult labor, multiple frequent labors and rough instrumental labors cause drastic trauma to the pelvic collagen with lacerations and subsequent atrophy and weakness. Several other factors contribute to exaggeration of the weakness of the pelvic collagen by atrophy and/or degeneration, e.g. hormone deficiency, especially after menopause, chronic or repeated genitourinary and rectoanal infections; in addition to congenital collagen weakness. 
Though some authors believe that the first vaginal delivery does the insult that affects the vagina and the intimately overlying urethra. ${ }^{6}$ The first vaginal birth is especially associated with the development of prolapse, whereas additional vaginal births do not show significant increases in the odds of prolapse. ${ }^{6} Y$ et cumulative affect of frequent multiple childbirth traumas and hormone deficiency delays the complaint till near menopause.

The weakness and rupture of the vaginal collagen sheet will manifest itself mostly in the transverse axis of the vagina. We can demonstrate this clinically and on imaging (Figs 9 and 10).

1. At first, there will be loss of the nulliparous $\mathrm{H}$-shape vagina, which changes into a transverse slit in parous women.

2. Then, further weakness, will lead to loss of vaginal rugae; the vaginal wall will be smooth without folds as can be seen clinically.

3. Further weakness and rupture of the vaginal collagen will induce vaginal wall redundancy and descent.

At the same time, the same childbirth trauma will injure the intimately closed IUS leading to SUI. In addition, the same trauma, in a backward direction, will injure the IAS causing $\mathrm{Fl}$.

The main function of the pelvic ligaments (uterosacral, great transverse cardinal cervical and pubocervical ligaments) is to assign the pelvic organs to the anatomical site and keep the pelvic organs in situ supported. The pelvic ligaments (which are composed of collagen bundles), when they suffer most of the childbirth trauma, the insult will lead to weakness of the pelvic ligaments, leading to their laxity and lengthening. This will induce drop of the pelvic organs beyond their anatomical site and produces vault and uterine prolapse.

\section{DEFECATION AND FECAL INCONTINENCE}

We are putting forward a recent concept on the pathophysiology of defecation. ${ }^{24,25}$

\section{Defecation (Fig. 13)}

The mechanism of defecation has two stages.

\section{First Stage of Defecation}

In infancy and early childhood, before training:

Through stretch receptors in the rectum, impulses of rectal fullness travel along pelvic parasympathetic, S2, 3 and 4 to spinal sacral centers leads to:

1. Reflex contraction of the rectal muscles.

2. The anal canal opens and the external anal sphincter (EAS) relaxes allowing defection to occur.

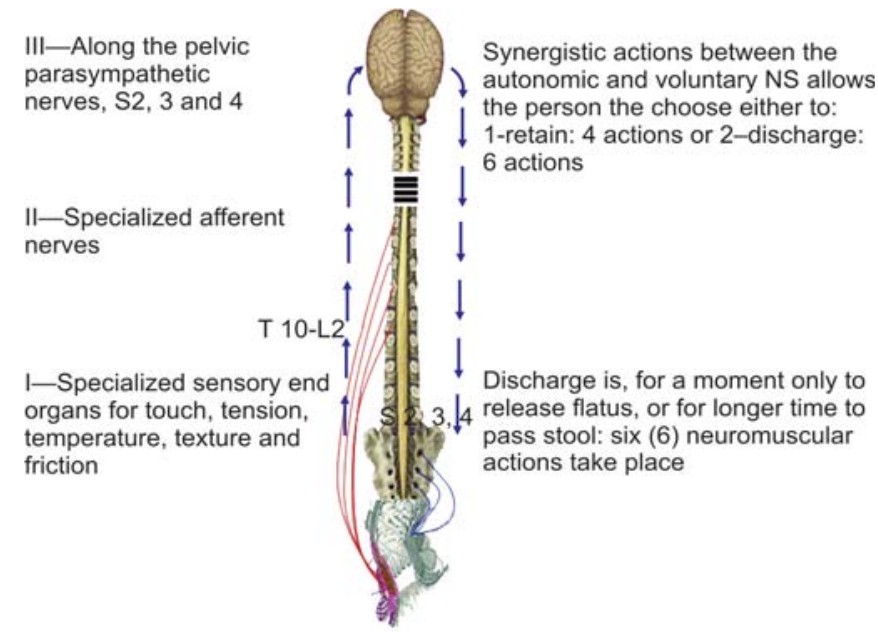

Fig. 13: Diagram, which shows the CNS control the mechanism of defecation

TheIAS: The IAS is a collagen muscle tissue cylinder that surrounds the anal canal; surrounded externally by the EAS. Its nerve supply is thoracolumbar al pha-sympathetic nerves from the hypogastric plexus (T10-L2).

Its functions are as follows:

1. On contraction, is to keep the anal canal closed and empty.

2. On relaxation, is to open the anal canal to allow passage of flatus and or stool.

\section{Second Stage after Training}

The mother starts to teach her child how to control himself. Gaining control is by maintaining high alpha-sympathetic tone at the I A S keeping it closed all the time until appropriate place and time are available.

On rectal distension, stretch receptors are stimulated. The sensation of rectal distension travels along the pelvic parasympathetic nerves to S2, 3 and 4 . In the rectoanal junction, there are specialized sensory end organs, e.g. $\mathrm{K}$ rause end-bulbs, Golgi-M azzoni bodies. Specialized afferent nerves for tension, temperature, texture, touch and friction subserve these organized nerve endings.

A $n$ intact sampling reflex allows the individual to choose whether to:

a. Retain the rectal contents or,

b. Discharge flatus and or stool.

A ccording to the available social circumstances, if the woman chooses to retain, then she will do the following steps:

1. She increases the acquired high alpha-sympathetic at the IAS, confirming its closure.

2. She confirms the closure of the EAS, which is a skeletal muscle, innervated with somatic nerve supply. 
3. She increases the contraction of the levator ani muscles to exaggerate the angle between the rectum and anal canal.

4. She inhibits the pelvic parasympathetic activity to the rectum and anal canal preventing their contractions.

Discharge is by relaxing the IAS and EA S for a moment only to release flatus, or for longer time to pass stool.

Wherever, appropriate place is available and there is a desire, under the control of the high CN S centers, through synergistic nervous actions between the autonomic and the voluntary nervous systems, six neuromuscular actions will occur:

1. The woman will lower the acquired high alphasympathetic tone at the IA S relaxing it, opening the anal canal.

2. Through the voluntary NS, she will relax the pelvic floor muscles thus widening the acute anorectal angle (changing it from acute to obtuse), to bring the anal canal and the rectum on one axis. She does so, through relaxing the pelvic floor muscles.

3. Through, voluntary NS, she will also relax the EAS, which is a skeletal muscle innervated by the pudendal nerve. Then two synergistic actions between the voluntary and autonomic nervous system will occur.

4. The abdominal muscles and the diaphragm contract to increase the intra-abdominal pressure and forcing the feces through the anal canal (The voluntary nervous system controls this action).

5. The smooth muscles of the distal colon and rectum contract, propelling the feces into the anal canal (The autonomic nervous system controls this action).

6. Followed by sequential contractions of the three parts of the EAS, deep, then superficial then the subcutaneous parts that will squeeze the anal canal propelling any residual contents and emptying the anal canal completely.

A n intact IAS, through the acquired high alphasympathetic tone, keeps the anal canal closed and empty. A torn weak IA S will lead to an open anal canal that is easy to discharge flatus or stool on rise of abdominal pressure (Figs 14 to 17).

Vaginal delivery causes lacerations of the posterior vaginal wall leading to posterior vaginal wall prolapse and causes lacerations of the collagen layer of the IAS, which is intimately related to the posterior vaginal wall.

Therefore, $\mathrm{FI}$ is prevalent in posterior vaginal wall prolapse (rectocele). Concomitant troubles, which occur, are vaginal prolapse, SUI and FI. 1, 5 and 6 (Fig. 17). Childbirth trauma causes the major insult, but aging and hormone deficiency (menopause) causes collagen atrophy and adds to weakness of the IUS, IAS and the vagina. ${ }^{8}$
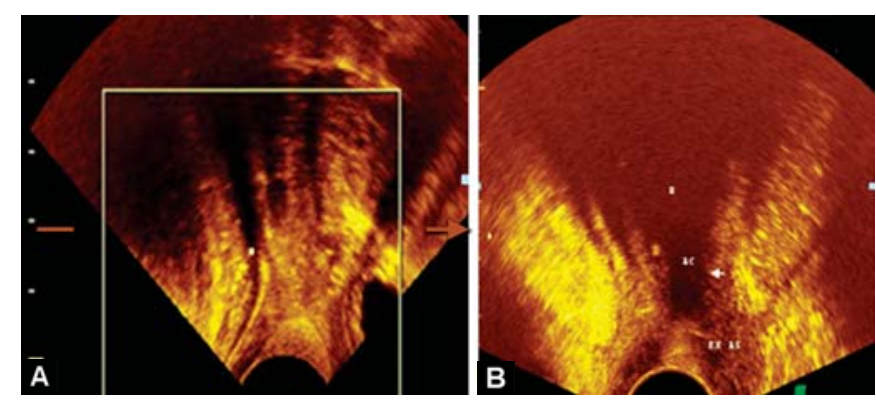

Figs 14A and B: Images with 3D US of the rectum and anal canal in normal continent woman (A) with healthy, intact IAS and a closed empty anal canal. In contrast, in (B) the IAS is torn leading to a widely open anal canal in a patient with $\mathrm{FI}$
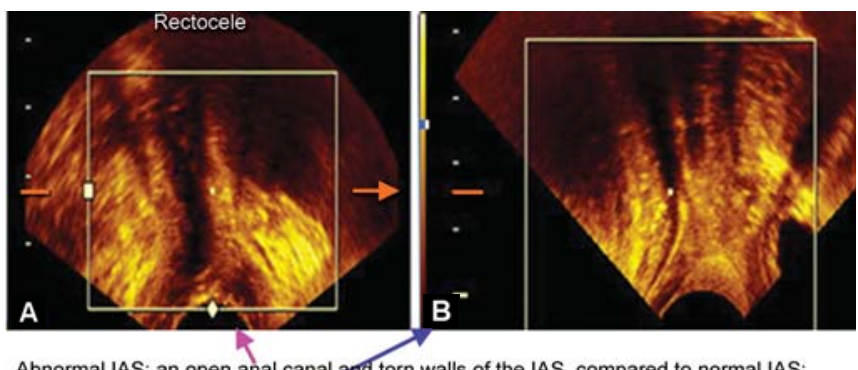

Abnormal IAS; an open anal canal and torn walls of the IAS, compared to normal IAS: Closed anal canal with intact walls of the IAS
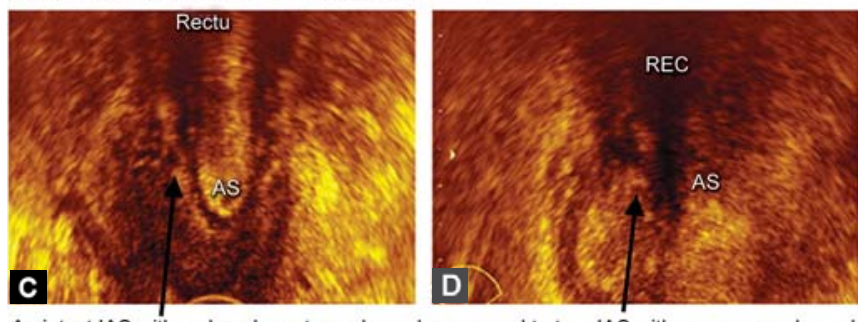

An intact IAS with a closed empty anal canal, compared to torn IAS with an open anal canal Figs 15A to D: Images with 3D US of the rectum and anal canal in normal continent woman (B) with healthy, intact IAS and a closed empty anal canal. In contrast, in (A, C and D) the IAS is torn leading to a widely open anal canal in a patient with $\mathrm{FI}$

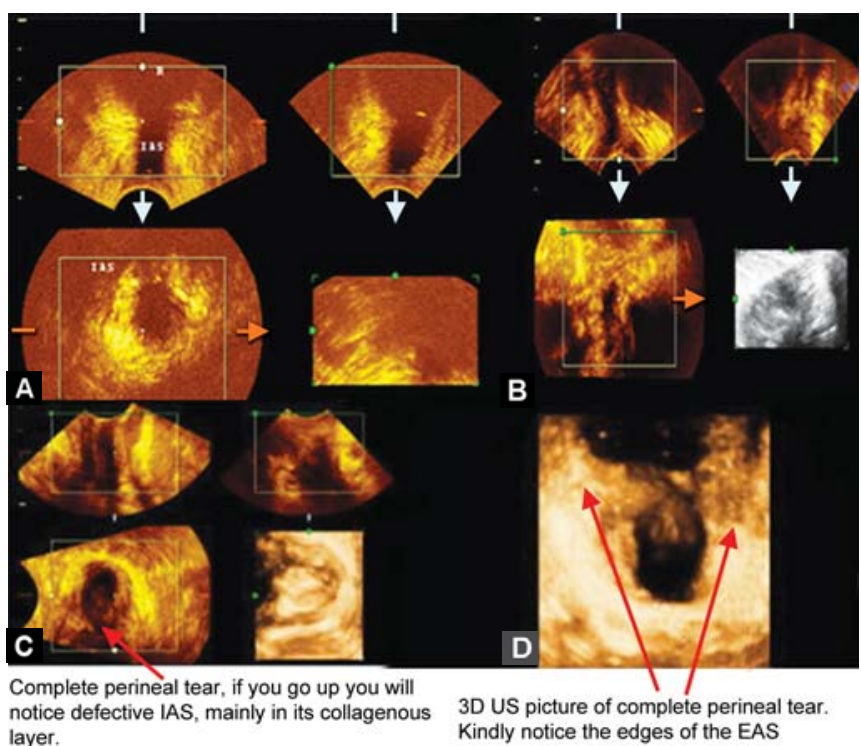
layer. Kindly notice the edges of the EAS

Figs 16A to D: Images with 3D US of the rectum and anal canal in patients with $\mathrm{Fl}$. Images in $\mathrm{C}$ and $\mathrm{D}$ are of complete perineal tear (fourth degree), the EAS is torn and appears as horseshoe; in addition, and the IAS is torn as well. Images in A and B are of the IAS, which are torn leading to an open dilated anal canal. The IAS appears like a horseshoe 


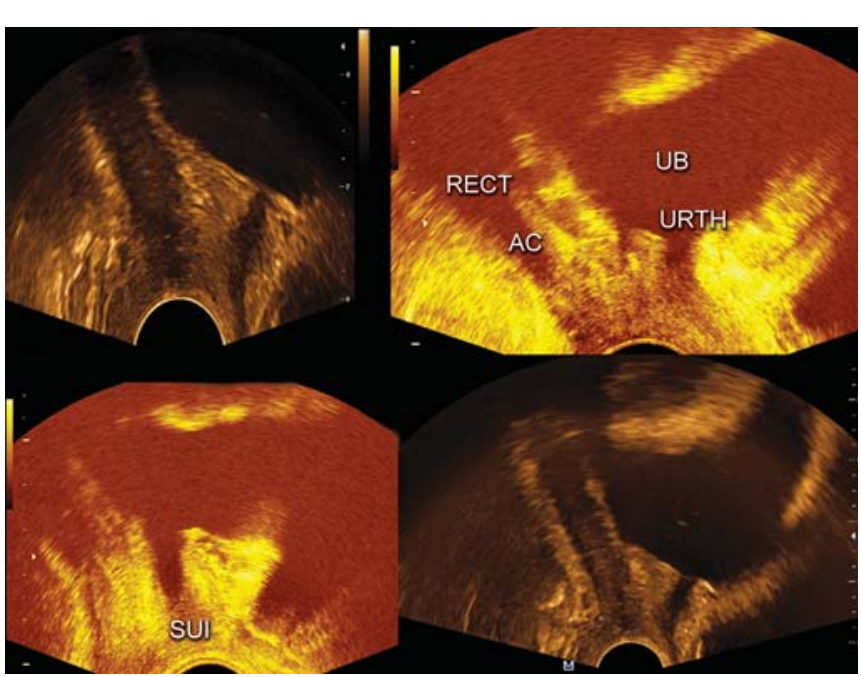

Fig. 17: Images by 3D US of patients who suffer from pelvic organs dysfunction, SUI, FI and vaginal prolapse simultaneously. The images show torn IUS and IAS

\section{RECONSTRUCTIVE SURGERY}

According to these novel concepts, a weak, torn IUS will lead to SUI. Vaginal prolapse is a consequence of weak, flabby, redundant torn vaginal walls. A weak, torn IA S will lead to $\mathrm{Fl}$.

Therefore, we have innovated an operation to treat SUI by exposing the rupture in the IUS and mending the torn sphincter. A t the same time, we have treated vaginal prolapse and FI by this novel operation ${ }^{26-30}$ (Figs 18 to 22).

\section{Urethro-ano-vaginoplasty' Repair Operation}

It consists of anterior and posterior sections.

In the anterior section, we correct the SUI and the anterior vaginal wall descent through the following steps (Figs 18 and 19).

We grasp the cervix with two pairs of cervical volsela. We inject about 10 to $20 \mathrm{ml}$ normal saline with adrenaline ( 2 per 1,000 concentration), beneath the vaginal wall to act as hydrodissection and vasoconstrictor. This separates the anterior vaginal wall from the posterior wall of the IUS. We do 2 to $4 \mathrm{~cm}$ transverse incision about $3 \mathrm{~cm}$ above the external cervical os. With a pair of dissecting scissors, we separate the anterior vaginal wall from the IUS. W e cut the anterior vaginal wall longitudinally from the transverse cut we made up to the submeatal sulcus, which correspond to the perineal membrane. We grasp each vaginal flap with three pairs of Kocher's forceps. The defect in the IUS will be apparent and on each side, we can clearly see two clear edges. One edge is of the anterior vaginal wall and the other is of the torn posterior wall of the IUS.

1. Expose the IUS (we dissect the IUS clear from the anterior vaginal wall).

2. M end the torn posterior wall of the IUS by several (6-8) simple interrupted sutures using number 0 polyglycan thread sutures (Figs 18A to E).

3. Strengthen the anterior vaginal wall by overlapping the two vaginal flaps, using a novel dragging sutures,
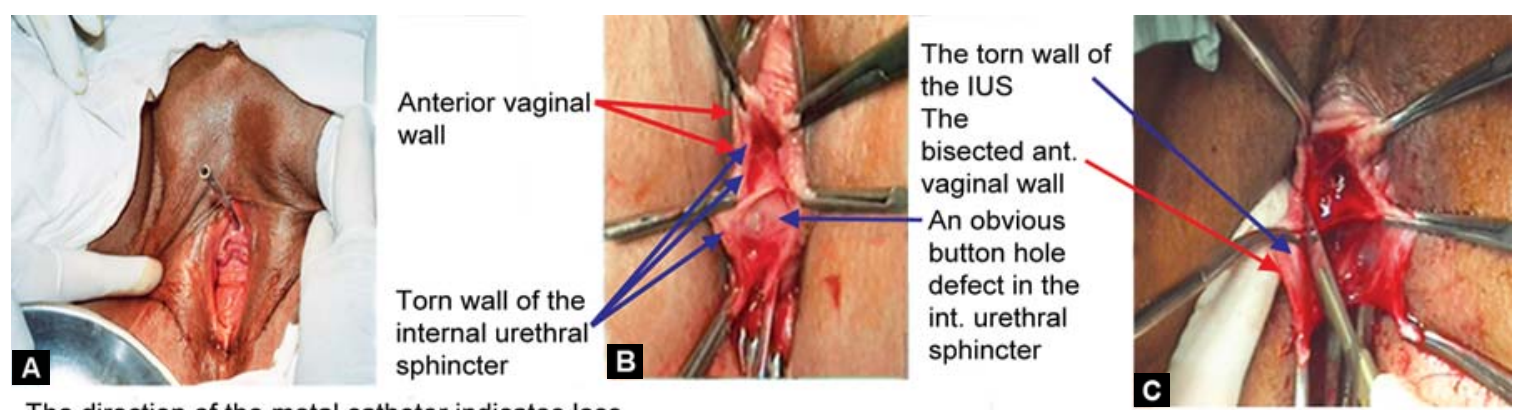

The direction of the metal catheter indicates loss of posterior $\mathrm{U}-\mathrm{V}$ angle
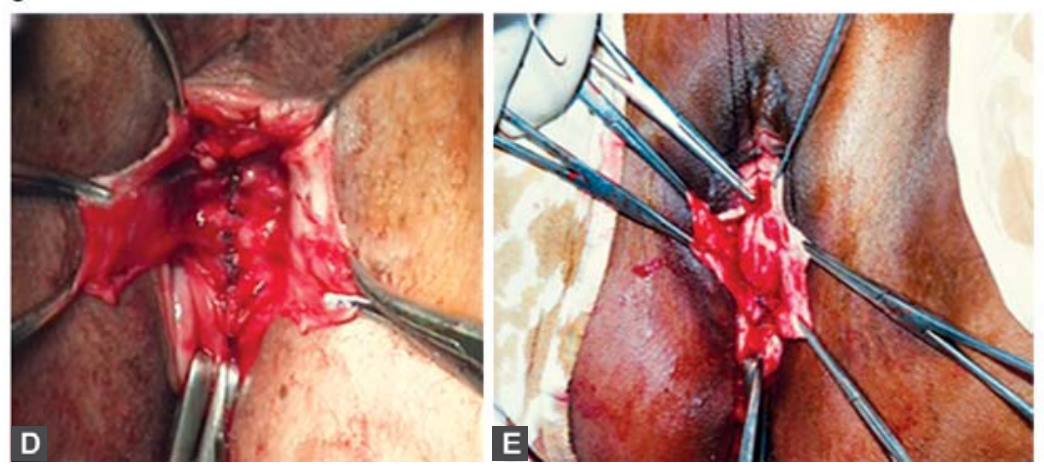

Figs 18A to E: Surgical photos of a patient with anterior vaginal wall prolapse, posterior vaginal wall prolapse, SUI and FI. The metal catheter is directed forward and upward $(A)$, which means loss of posterior urethrovesical angle. We dissect the IUS from the anterior vaginal wall $(B$ and $C)$ and mend the torn IUS with simple interrupted sutures ( $D$ and $E$ ) 

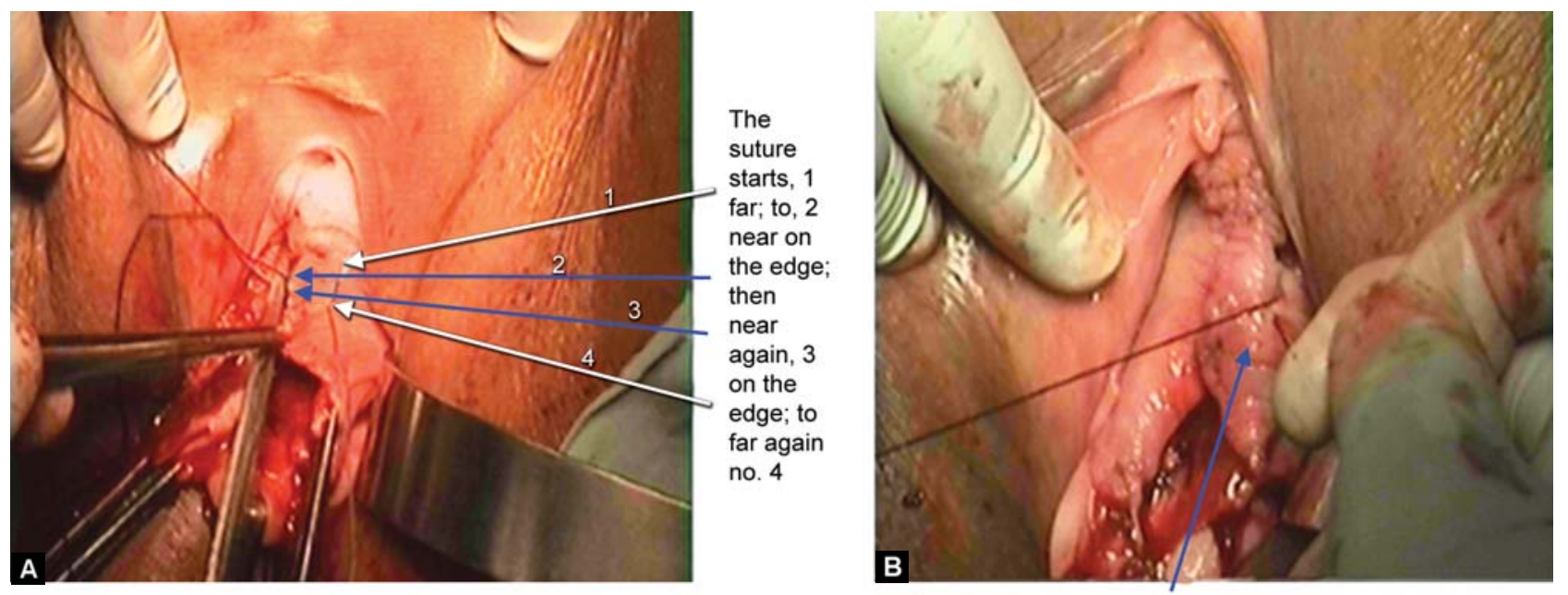

On tying the 2 arms of the thread together, this brings the rt. flap beneath the left
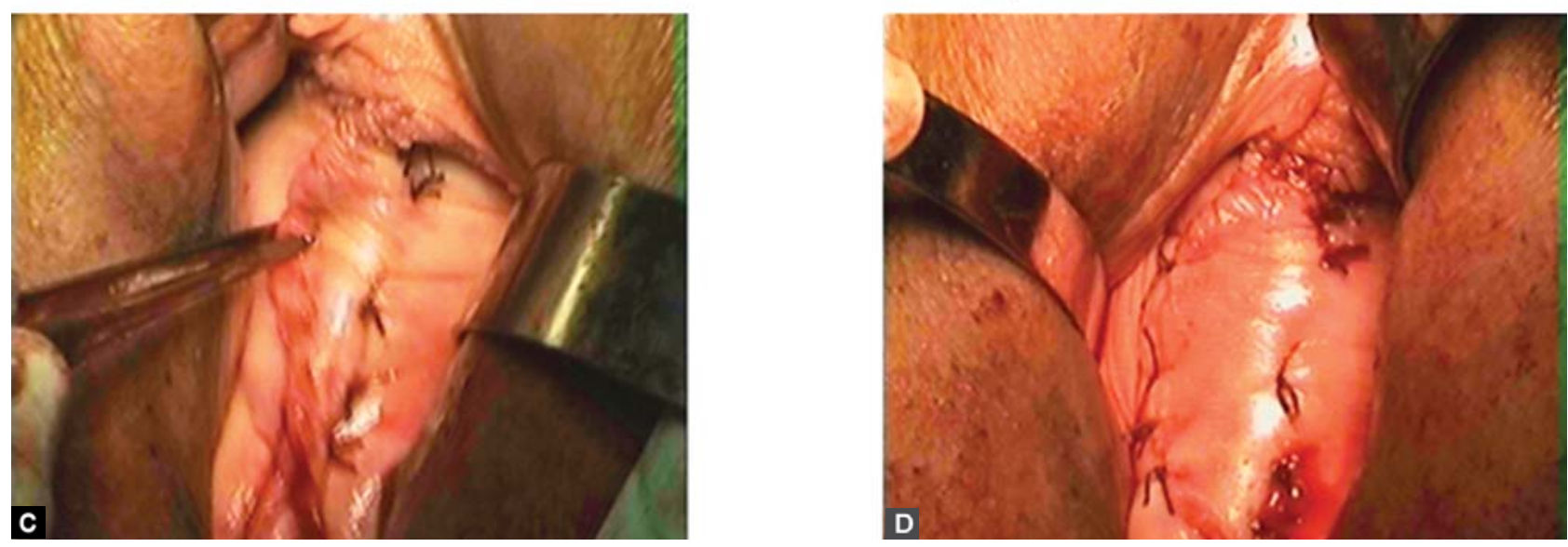

Figs 19A to D: After mending the IUS, we do overlapping of the two vaginal flaps as seen in the photos. We bring the right vaginal flap underneath the left vaginal flap with this novel dragging suture as seen in $(A)$ and $(B)$, repeating it 4 to 6 times. Then, we suture the free edge of the left vaginal flap as far laterally in the vagina on the right as seen in $C$ and $D$. Thus, we strengthen the anterior vaginal wall and add extra strength to the mended IUS

dragging the right vaginal flap underneath the left vaginal flap. Then we do suturing the free edge of the left vaginal flap as far lateral on the right side of the vagina. So we strengthen the anterior vaginal wall and decrease its width, we also add extra support to the mended IUS, and preserve the body collagen.

In the posterior section, we do as shown in Figures 20 to 22 .

We do hydrodissection between the posterior vaginal wall and the anal canal and the rectum; and in the perineum as done anteriorly.

We do a V-shape incision at the line between the posterior vaginal wall and the perineal skin down to the perineum. Then we try to create a space between the posterior vaginal wall and the anal canal by sharp and blunt dissection. Next with a pair of dissecting scissors, we separate the posterior vaginal wall from the rectum and anal canal. Then we cut the posterior vaginal wall longitudinally in the midline to beyond the apex of the prolapse protrusion.
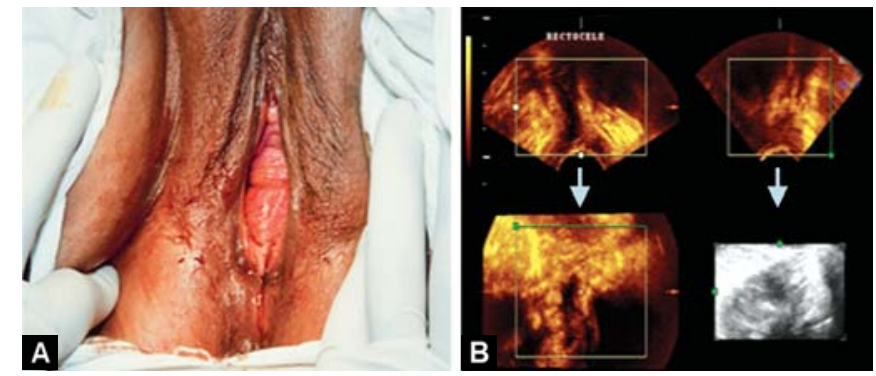

Figs 20A and B: The posterior vaginal wall when seen without straining, this means posterior vaginal wall prolapse as seen in (A). Image (B) is 3D US showing rectocele of the same patient who suffers FI

We hold each vaginal flap with three pairs of Kocher's forceps. We will clearly see two different edges on each side, one is the vaginal edge, and the other is the anterior wall of the torn IAS.

1. We dissect the torn IAS clear from the posterior vaginal wall.

2. M end the torn wall of the sphincter by serial interrupted simple sutures with number 0 polyglycan thread. 


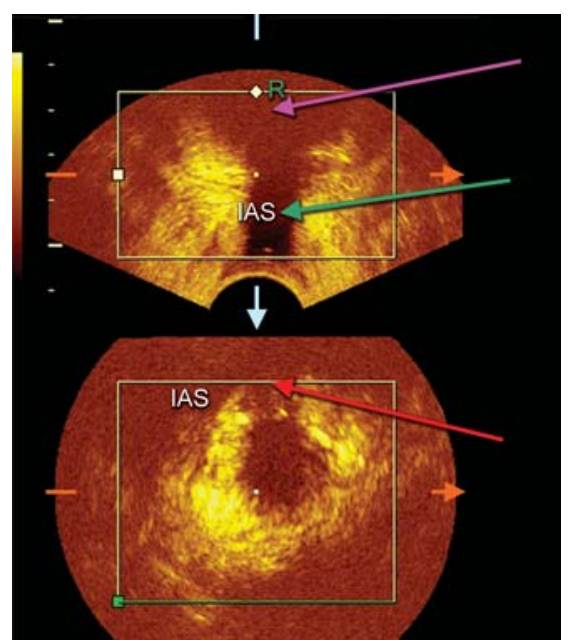

Fig. 21: Images with 3D US of a patient with FI that show torn IAS. The anal canal is wide and open and the IAS is horseshoe

\section{A pproximate the two-levator ani muscles.}

4. Strengthen the posterior vaginal wall by overlapping the two vaginal flaps; thus, we also add extra support to the mended IA S and keeping the natural body collagen.

5. Repair the perineum. We put a Foley's catheter and vagina pack for 24 hours.

\section{CONCLUSION}

Scanning with 3D US has the advantages of being easy to do, fast to do, not invasive and not expensive. In few cases of SUI, the resting Pura may not be low, yet there is clinical urinary incontinence; those cases have linear cracks in the IUS, which we can see on scanning with 3D US.

We conclude that damage of the IUS leads low Pura and SUI.

Childbirth trauma causes damage to the collagen layer of the vagina that leads to redundancy of the vagina and vaginal prolapse.

Injury of the anal sphincters leads to $\mathrm{FI}$. W e can diagnose the damage of the EAS clinically, but the damage of the IA S needs scanning with 3D US. Thus damage of the pelvic collagen leads to SUI, genital prolapse and FI. The damage is mostly traumatic from childbirth injury. Hormone deficiency leads to atrophy and chronic or repeated pelvic infections lead to degeneration of the collagen, which make the condition worse.

Thus, though the pelvic floor may suffer some damage from childbirth trauma and hormone deficiency, yet the troubles of urinary incontinence, genital prolapse and $\mathrm{FI}$ are due to pelvic organs dysfunction and not pelvic floor
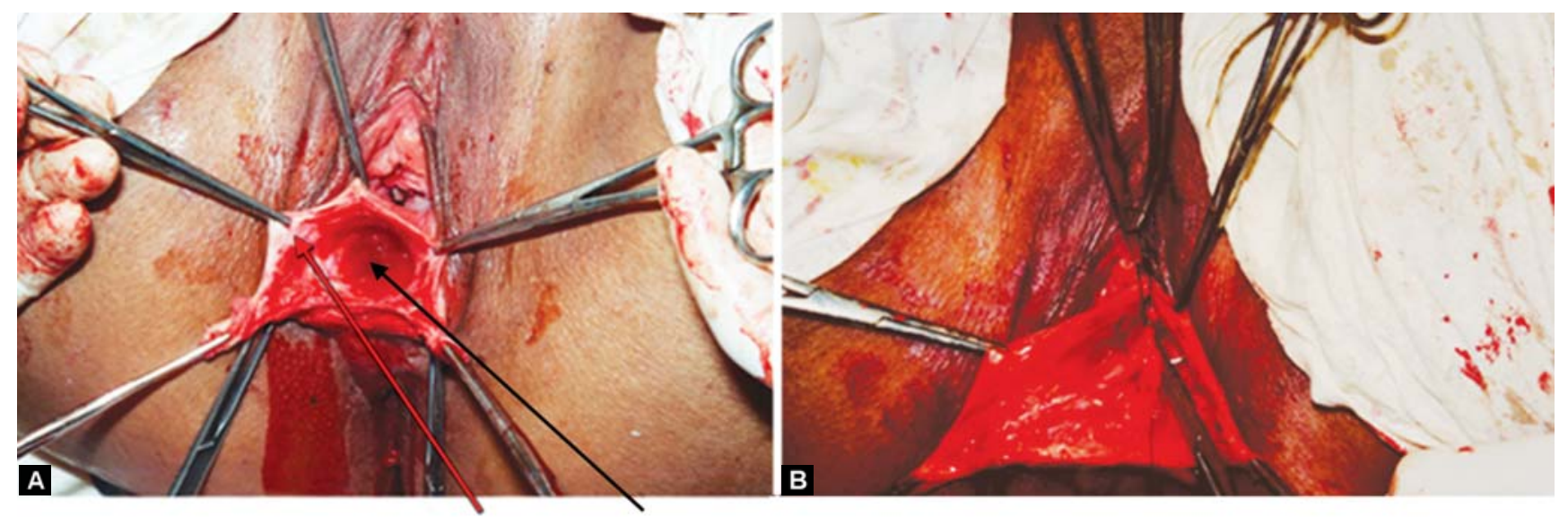

Kindly notice 2 edges, the post. vaginal wall edge and the ant. wall of the IAS torn
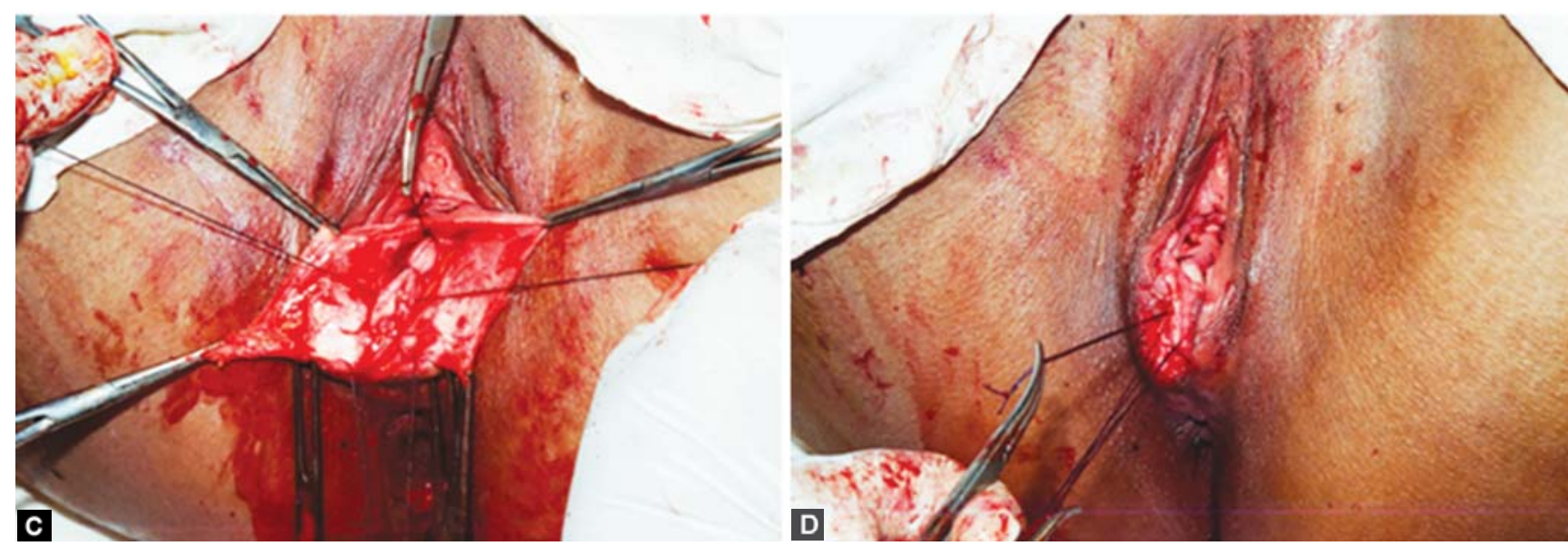

Figs 22A to D: Surgical steps of posterior repair. We dissect the IAS from the posterior vaginal wall (A). We mend the sphincter (B and $\mathrm{C})$, in addition, we approximate the two levator ani muscles by two stitches, but we do not tie them till we finish overlapping the posterior vaginal wall (D) 
dysfunction. The new repair operation is a simple successful vaginal operation with no use of synthetic materials with its complications. It corrects the anatomy of the pelvic organs in order to restore their normal physiology.

\section{REFERENCES}

1. Liedl B, M akrovsky O, W agenlehner F, Gunnemann A. The role of altered connective tissue in the causation of pelvic floor symptoms. A lhasso A, Fernando A (Eds). U rinary incontinence. 2012 A pr;3-20. A vailable from: www.Intechopen.com.

2. Corton MM. A natomy of pelvic floor dysfunction. Obstet Gynecol Clin N A m 2009;36:301-19.

3. Irwin DE, M ilsom I, Hunskaar S, et al. Population-based survey of urinary incontinence, overactive bladder, and other lower urinary symptoms in five countries: Results of the EPIC study. Eur U rol 2006;50:1306-15.

4. Wagg AS, Cardozo L, Chapple C, et al. Overactive bladder syndrome in older people. BJU Int 2007;99:502-09.

5. Petros PE. The female pelvic floor function, dysfunction and management according to the integral theory. B erlin-Heidelberg: Springer V erlag 2010:1-100.

6. Quiroz LH, M unoz A, Shippey SH, Gutman RE, Handa VL. Vaginal parity and pelvic organ prolapse. J Reprod Med 2010;55:93-98.

7. de B oer TA, Salvatore S, Cardozo L, Chapple C, K elleher Y C, van Kerrebroeck $P$, et al. Pelvic organ prolapse and overactive bladder. N eurourol U rodynam 2010;29:30-39.

8. EI Hemaly AKM, M ousa LA, K andil IM. The concept and pathophysiology of urinary incontinence. In: Alhasso $A$, Fernando A (Eds). U rinary Incontinence 2012 A pr;145-60. A vailable from: www. Intechopen.com.

9. EI Hemaly AKMA, Mousa LA. Micturition and urinary continence. Int J Gynecol Obstet 1996;42:291-92.

10. EI Hemaly A K M, K andil IM, K urjak A, M ousa LAS, Kamel $H H$, Serour A G. Ultrasonic assessment of the urethra and the vagina in normal continent women and women suffering from stress urinary incontinence and vaginal prolapse. Donald School J Ultrasound Obstet Gynecol 2011 Oct-Dec;5(4):330-38.

11. EI Hemaly AKM A, M ousa LAE. Stress urinary incontinence: A new concept. Eur J Obstet Gynecol Reprod Biol 1996;68: 129-35.

12. El Hemaly A K M. U rinary incontinence in gynecology: A review article. A vailable from: http://www.obgyn.net/urogyn/ urogyn.asp?page=/urogyn/articles/abs-urinary_incotinence gyn_ehemaly.

13. El Hemaly AKMA. Nocturnal enuresis: Pathogenesis and treatment. Int Urogynecol J Pelvic Floor Dysfunct 1998;9: 129-31.

14. El Hemaly AKM . Nocturnal enuresis: A novel concept on its pathogenesis and treatment. A vailable from: http:// w w w . obgyn.net/urogynecolgy/? page=articles/ nocturnal_enuresis.

15. El Hemaly AKM. Nocturnal enuresis: A n update on the pathogenesis and treatment. A vailable from: http:// www .obgyn.net/urogynecology/?page=/E N HLIDH/PUBD/
FEA TURES/Presentations/ N octurnal_Enuresis/nocturnal_ enuresis.

16. Ibrahim M Kandil, A bdel Karim M El Hemaly, M ohamad M Radwan. UItrasonic A ssessment of the Internal U rethral Sphincter in Stress U rinary Incontinence. The Internet J ournal of Gynecology and Obstetrics 2003;2(1).

17. EI Hemaly A K M, K andil IM , EI M ohamady BE. M enopause and voiding troubles. A vailable from: http://www.obgyn.net/ displayppt.asp?page=/E nglish/pubs/features/presentations/E IHemaly03/el-hemaly03-ss.

18. EI Hemaly AK M A , K andil IM. Stress urinary incontinence SUI facts and fiction. Is SUI a puzzle?! A vailable from: http:// www.obgyn. net/displayppt.asp?page=/English/pubs/features/ presentations/El-Hemaly/el-hemaly-ss.

19. EI Hemaly AK, M aksoud NA, M ousa LA, K andil IM, A nwar $A, E I$ Hemaly MAK, et al. Evidence based facts on the pathogenesis and management of SUI. A vailable from: http:// www.obgyn. net/displayppt.asp?page=/English/pubs/features/ presentations/EI-Hemaly02/el-hemaly02-sS.

20. A thanasiou S, K hullar V, B oos K, et al. Imaging the urethral sphincter with three-dimensional ultrasound. Obstet Gynecol 1999;94(2):295-301.

21. DeL ancey J0. Structural aspects of the extrinsic continence mechanism. Obstet Gynecol 1988;72(3 Pt 1):296-301.

22. U mek WH, Laml T, Stutterecker $D$, et al. The urethra during pelvic floor contraction: Observations on three-dimensional ultrasound. Obstet Gynecol 2002;100(4):796-800.

23. D efreitas GA, W ilson TS, Zimmern PE, et al. Three-dimensional ultrasonography: A n objective outcome tool to assess collagen distribution in women with stress urinary incontinence. U rology 2003;62(2):232-36.

24. El Hemaly AKM, Kandil IM, M ousa AKLAS, Kamel HH, Serour A G. U Itrasound assessment of the internal anal sphincter in women with fecal incontinence and posterior vaginal wall prolapse (rectocele). Donald School J U Itrasound Obstetr Gynecol 2011 Oct-Dec;5(4):330-42.

25. El Hemaly AKM, M ousa LAS, K andil IM, El Sokkary FS, Serour AG, Hussein H. Fecal incontinence: A novel concept. The role of the internal anal sphincter (IAS) in defecation and fecal incontinence. Gynaecologia Et Perinatologia 2010; 19(2):79-85.

26. El Hemaly AKM, M ousa LAS, K andil IM, El Sokkary FS, Serour AG, Hussein $H$. Surgical treatment of stress urinary incontinence, fecal incontinence and vaginal prolapse by a novel operation: 'U rethro-ano-vaginoplasty.' Gynaecologia Et Perinatologia 2010 J ul-Sep;19(3):129-88.

27. EI Hemaly A K M, K andil IM , Radwan M M. U rethroraphy: A new technique for surgical management of stress urinary incontinence. A vailable from: http://www.obgyn.net/urogyn/ urogyn.asp?page=/urogyn/articles/new-tech-urethro.

28. El Hemaly A K M , K andil IM, Rizk M A, Nabil A bdel M aksoud H, Radwan M M , EI Shieka K Z, et al. U rethro-raphy: The new operation for the treatment of stress urinary incontinence, SUI, detrusor instability, DI, and mixed-type of urinary incontinence; short and long term results. Available from: http:// www.obgyn.net/urogyn/urogyn.asp?page=urogyn/articles/ urethroraphy- 09280 . 
29. El Hemaly AKM, Kandil IM, Rizk MA, El Hemaly MAKM. U rethro-plasty: A novel operation based on a new concept, for the treatment of stress urinary incontinence, SUI, detrusor instability, DI, and mixed-type of urinary incontinence. A vailable from: http://www.obgyn.net/urogyn/urogyn.asp?page=/urogyn/ articles/urethro-plasty_01.

30. El Hemaly A K M , K andil IM , M ousa LA S, EI Hemaly M A KM . U rethro-vaginoplasty: A $n$ innovated operation for the treatment of stress urinary incontinence (SUI), detursor overactivity (DO), mixed urinary incontinence and anterior vaginal wall descent. A vailable form: http://www.obgyn.net/urogyn/urogyn.asp?page=/ urogyn/articles/urethro-vaginoplasty_01.

\section{ABOUT THE AUTHORS}

Abdel Karim M El Hemaly (Corresponding Author)

Professor, D epartment of O bstetrics and G ynecology, A I A zhar U niversity

Cairo, Egypt, Phone: +2 01001577969, e-mail: profakhemaly@ hotmail.com

\section{Laila A Mousa}

Professor, Department of Pathology, A I A zhar University, Cairo, Egypt

\section{Asim Kurjak}

Professor, Department of Obstetrics and Gynecology, M edical School University of Zagreb, Zagreb, Croatia

\section{Ibrahim M Kandil}

Department of Obstetrics and Gynecology, Faculty of M edicine Al A zhar University, Cairo, Egypt

\section{Ahmad G Serour}

Lecturer, Department of Obstetrics and Gynecology, Faculty of M edicine and International Islamic and Population Center, A I A zhar University, Cairo, Egypt 